\title{
ORGANISATIONAL MANAGEMENT IN PUNE'S AUTO ANCILLARIES
}

\author{
Dr. MANISHA PALIWAL ${ }^{1} \&$ ASHOK RASKAR ${ }^{2}$ \\ ${ }^{I}$ Professor and Head, Centre for Gender Studies, Vaikunth Mehta National Institute of Cooperative \\ Management (VAMNICOM), Ganeshkhind Road, Pune, Maharashtra, India
}

${ }^{2}$ Research Scholar Organization Management Sinhgad Institute of Management (SIOM) Vadgaon (BK),

Pune, Maharashtra India

\begin{abstract}
With a Compounded Annual Growth Rate (CAGR) of around 6\% over the last six years (2012-13 to 2017-18) the Indian Automobile Industry has been a steady performer delivering a reasonable growth year-on-year. A research was carried to study Organizational Management in Pune's Auto Ancillaries \& impact on their performance. The research had the objectives of studying the Organizational and Management practices followed by the Pune Auto Ancillary sector in comparison with All India Auto Ancillary units. The aim was to find out gaps between the Organizational and Management practices followed by the Indian and Pune Auto Ancillary sector and to assess the impact of these gaps on performance of Pune Auto Ancillary sector. Before the study was carried out a review of the literature was done and this article presents its results.

KEYWORDS: Auto Ancillary Sector, Organization and Management Practices \& Literature Review
\end{abstract}

Received: Mar 15, 2019; Accepted: Apr 05, 2019; Published: May 03, 2019; Paper Id.: IJHRMRJUN201910

\section{INTRODUCTION}

India has started to attract important attention as a destination of manufacturing, pursuing the rise of the Global Automotive industry. Hence, the auto industry of India has the possibility to appear as one of the biggest in the world (Saranga, n.d). In the present scenario, India is fourth biggest market of commercial vehicle and, second biggest market of two-wheelers and eleventh biggest market of passenger car. The Indian Auto Component Industry is one of the fastest growing industries and is riding on the success of the automobile sector (FundIndia, 2015). Coupled with growing demand and technological advancements, the auto component industry in India has emerged as a key market in Asia as well as in the world. The country currently supplies, auto components to a number of international automobile makers, such as General Motors, Toyota, Ford and Volkswagen, amongst others. India is presently the world's third largest exporter of two wheelers after China and Japan. Before the full study was undertaken a literature review was done. This article presents the same.

\section{REVIEW OF LITERATURE}

The literature review was carried with the following objectives

- To review the literature on the Automobile sector (since Auto Ancillary sector is directly dependent and an important part of the Automobile sector),

- To review the literature on Auto Ancillary sector and 
- $\quad$ To review the literature on Organizational and Management Practices

McKinsey (2018) in its article titled "The future of mobility in India's passenger-vehicle market", has carried an appeal to the incumbents in the automotive industry for gearing up for a changing landscape as India grows into the world's third-largest passenger-vehicle market and global trends disrupt the sector. It adds that India is expected to emerge as the world's third-largest passenger-vehicle market by 2021. While it took India around seven years to increase annual production to four million vehicles from three million, the next milestone - five million-, however, is expected in less than five years. Hitting that mark will depend on today's rapid economic development continuing, with a projected annual GDP growth rate of $7 \%$ through 2020, ongoing urbanization, a burgeoning consuming class, and supportive regulations and policies. The report suggests the following measures -

- $\quad$ Reinventing the business

- Make in India for India

- Going granular

- $\quad$ Partnering to build relevant assets

- Empowering the organization in India and investing in talent

- Embracing technology

In conclusion, the report says that "India's automotive industry and market are on the cusp of major change. The opportunities generated by the disruptions ahead can change the competitive game for players willing to step beyond their traditional roles and engage with customers in this new, digital environment."

KPMG (2010) in its report titled “The Indian Automotive Industry - Evolving Dynamics”, has concluded that "India's automobile industry is poised at the start of an exciting phase of growth, not all of which may derive from manufacturing conventional fuel-based vehicles. Various possibilities ranging from developing vehicles based on alternate fuels to collaborating with sometimes rivals, have the potential to open fresh avenues for growth." It has given the suggestions that include concentration of resources and technical ingenuities may be vital to generate workable economies of scale, going for greater specializations, such as that witnessed in the IT industry, to simplify processes and reduce investment need, improving distribution networks and targeting niche markets across all vehicle types, under-served demographics such as young people, women and rural customers and establishing better links with support industries such as battery manufacturer's to help drive down costs of making and maintaining green vehicles.

Ernst \& Young (2011), in their research report have stated that stakeholders across the Indian passenger vehicle industry are likely to be impacted by fast changing events across the automotive ecosystem beitin the operating environment, customer preferences, competition, distribution channel or supply chain. It has posed five key questions as under

- How will products need to adapt?

- How will business models need to adapt?

- What are the new market dynamics? 
- What are the supply/ value chain issues and implications?

- How will demand for vehicles and mobility evolve?

Sharma (2006) analyzed the performance of the Indian auto industry with respect to the productivity growth. Partial and total factor productivity of the Indian automobile industry was worked out for the period from 1990-91 to 2003-04, using the Divisia- Tornquist index for the estimation of the total factor productivity growth. The author founds that the domestic auto industry had registered a negative and insignificant productivity growth during the last one and a half decade. Among the partial factor productivity indices only labour productivity saw a significant improvement, while the productivity of other three inputs (capital, energy and materials) didn't show any significant improvement. Labour productivity had increased mainly due to the increase in the capital intensity, which had grown at a rate of 0.14 per cent per annum from 1990-91 to 2003-04.

Veloso and Kumar (2002) provided an overview of the major trends taking place in the global automotive industry, with a focus on the Asian market. Consumer preferences, Government regulations and intense competition were found to be driving the firms towards new technologies, modernization, research and changes in design and production. Market saturation in Triad regions (the United States, Western Europe and Japan) and rapid emergence of markets in Asia have led to increasing diversity in market needs. This resulted in many models and segments coming up rapidly.

Narayanan (2004) used a two-way fixed effects estimation of the firm growth as a function of variables capturing technology, such as R\&D expenditure as a proportion of sales, foreign equity participation and import of capital goods. He concluded that role of technology depends on the technological regime in which the firm operates. In a licensed regime, firms with foreign equity grow faster because of better access to resources and technology. In a deregulated regime, import of capital goods has been the technology-related variable that triggered growth. In a liberal regime, growth is positively influenced by the intra-firm technology transfer.

Kathuria (1996) analyzed the Commercial Vehicles (CV) industry in India in some details. He dwelled on the concepts of vertical integration and subcontracting, production technology and technological change. After an overview of the global auto industry, Kathuria traced the developments in the Indian auto industry from the 1950s to 1991. To evaluate the competitiveness of Indian commercial vehicle manufacturers in the domestic market, growth trends, structural trends, market shares, profitability, productivity ratios, prices, quality, dealer network and performance were analyzed. Macro and micro performance of India's vehicle exports with major markets and Indian vehicle characteristics were outlined, along with an analysis of global demand patterns. Domestic resource costs and global comparison of prices, credit and service are the other international trade-related aspects were analyzed in this study. On vertical integration, the analysis led to the conclusion that the Indian CV industry needed to learn from the international experience to get into subcontracting and buying-in. Lack of scales and high inventories had impeded the competitiveness of Indian CV firms in the 1980s.

McKinsey (2005) predicted the growth potential of India-based automotive component manufacturing at around 500 per cent, from 2005 to 2015 . This report described the initiatives required from industry players, the Government and the ACMA to capture this potential. This study was based on interviews and workshops with 20 suppliers and 7 OEMs and survey with ACMA members. Increase in cost pressures on OEMs in developed countries, coupled with the emergence of skilled, cost-competitive suppliers in Low Cost Countries (LCCs), is likely to facilitate further acceleration of sourcing of automotive components from LCCs. The analysis identified strong engineering skills and an emerging culture of 
cost-competitiveness as the major strengths of the Indian auto component sector, while its weaknesses include slow growth in domestic demand and structural disadvantages such as power tariffs and indirect taxes.

Piplai (2001) examined the effects of liberalization on the Indian vehicle industry, in terms of production, marketing, export, technology tie-up, product up gradation and profitability. Till the 1940s, the Indian auto industry was non-existent, since automobile were imported from General Motors and Ford. In the early 1940s, Hindustan Motors and Premier Auto started, by importing know-how from General Motors and Fiat respectively. Since the 1950s, a few other companies entered the market for two-wheelers and commercial vehicles. However, most of them either imported or indigenously produced auto-components, till the mid-1950s, when India had launched an import substitution program, thereby resulting in a distinctly separate auto-component sector.

Economic Times (2018), in the article titled "ICRA upgrades Indian auto component industry's growth in 13-15\% in FY18" has cited the ICRA report showing high expectations from the Auto Ancillary sector in the backdrop of robust growth expectation in domestic PV, CV, tractor and 2W segment. ICRA's sample of 48 auto ancillaries, comprising around $26 \%$ of the industry's turnover, grew 18.5\% revenue-wise during Q3 FY2018. The same appeared stronger on a low base of last fiscal, where overall performance was impacted by demonetization. Overall, during 9MFY2018, the sample space grew by $12.3 \%$, which was better than the earlier 9\%-11\% growth estimate for FY2018e. Given strong revenue growth the growth estimates have been revised upward for FY2018e to $13-15 \%$.

India Briefing (2018) in the report titled "Auto Components Manufacturing in India: Robust Investment Outlook, Growth Potential" has quoted SunjayKapur, CEO of the Sona Group, a US\$800 million multinational firm and leading Indian auto component manufacturer saying, "The auto components sector in India has reached a mature stage, and is well poised for growth. The next few years will see growth in all segments in the domestic industry making India a strong base for the global export market. What is needed now is investments in technology and people in the tier II and tier III space in India. This will be a challenge as we see OEMs grow in India."

CARE Ratings (2017) in the report has reported that "As per the Automotive Mission Plan 2016-26 (AMP), the Indian auto component industry may attain an impressive USD 200 billion in revenue by 2026, with exports of USD 80 billion. The Indian Automotive Industry will be among the top three of the world in the area of engineering, manufacturing export of vehicles and components. It is estimated that the demand of vehicles will reach 66.3 to 75.8 million units in the same year. Contribution of Auto component industry in India's GDP will account to as much as 5\% to $7 \%$ by 2026. Exports of auto components grew at a CAGR of 14\% to USD 10.8 billion in 2015-16 from USD 3 billion in 2005-06."

India Ratings and Research (Ind-Ra) (2017) in its research report has stated that "Although Ind-Ra expects the operating costs in the industry to increase in FY19 on account of cost escalation towards the implementation of changing regulatory norms and raw material pricing pressures, the agency believes that this will have a limited impact on the profitability of the sector companies as the volume growth would bring operating efficiencies and pass-through agreements with OEMs to limit the impact of raw material price fluctuation.

Further, Ind-Ra expects the CAPEX of sector companies to relatively rise on developing products to meet stricter emission standards and higher R\&D spending towards the greener technologies and solutions. Also, the agency expects consolidation in the sector with some larger players embracing inorganic growth in the medium to long term. Nevertheless, the credit metrics of the sector companies are likely to remain stable in FY19 due to comfortable cash flows and liquidity." 
ASA \& Associates (2015) in their report on the Auto Ancillaries have outlined the challenges being faced by the sector. "There are also many challenges which the auto component industry faces such as a high cost of capital and imperfect capacity utilization. The Industry also faces major infrastructural challenges and costs with respect to an inadequate transportation system such as roads and ports. Power also poses a huge infrastructural challenge. Currently Imports are higher than Exports, which also pose a problem in the auto component industry. A major issue is the sale of counterfeited cheaper parts which result in a loss of revenue and market for the industry. The industry also faces obstacles in the form of deficiency of skilled manpower and R\&D competency andecosystem”, it concludes.

In its research report ICICIdirect.com (2014) has highlighted the role of "Make in India" campaign by saying that "The policy aims to develop India into a hub for manufacturing and exporting small cars and auto ancillaries. The government has outlined measures such as removal of the clause pertaining to minimum foreign direct investment, permitting foreign automobile manufacturers to set up wholly-owned subsidiaries in India. Low cost centers (LCC) include China, Mexico, South Korea, Poland, Hungary, Thailand, Brazil, India, Malaysia and Russia. Exports from LCCs grow on account of factors such as the presence of a large domestic market, global OEMs' presence in the LCC market and inherent cost advantages in terms of lower cost of living, cheap labour availability, subsidies to the industry, etc. Global OEMs like Volkswagen, General Motors (GM), Ford and Toyota are present in most of these countries and aim at developing sourcing bases (through global and local vendor partners) which can cater to domestic and global sourcing needs at lower costs."

e-Research \& Publications (2011) in its outlook for the Indian Auto Ancillary Sector has stated that the trend of auto component majors getting into multiple automotive segments to shield from market fluctuation will be witnessed more in the coming years. If has further said that low vehicle scrappage rate, need for frequent replacements and growing used vehiclemarket will drive the auto componentaftermarket. Finally, it said that in order to improve cost competitiveness during market slowdown, vehicle manufacturers are reducing in-house component production and opting for outsourcing to reduce investment and technology up-gradation. This trend is expected to expand the domestic auto ancillary market and increase competitiveness.

Kiel Institute Unit (2018) carried a mega comparative study of German and US companies with reference to Management practices. The questions on management practices covered issues related to monitoring, targets and incentives. Additionally, items on work-family balance and health promoting measures were also taken. The performance measures included questions on sales, exports, innovations etc.

Shoko Haneda and Keiko Ito (2017) in their article highlighted the fact that product innovation is positively correlated with the number of practices implemented. Further they found that personnel assessment reflecting R\&D outcomes had a large effects on product innovation and that drastic organizational change helps to accelerate innovation success.

Nicole Papa (2017) in an article said that "The leadership and management of an organization have a deep impact on the culture, direction and public image of the organization. Organizational management is the ability to govern and manage the people that make up a group or team with the purpose of enforcing the organization's goals and standards, according to the Nonprofit Good Practice Guide. Organizational Management is the leading authorities over a group of people that are responsible to cast vision, implement change and plan for the future of the organization. Various leadership practices and expectations are needed for leaders to make a positive and effective impact on the organization they are leading." 
Raffaella Sadun (2017) in her article "Google's Secret Formula for Management? Doing the Basics Well”, has surprised many by stating that some of the best management practices as released by Google actually focus a lot on doing basic things right. "Turns out a lot of its management tools focus on some pretty basic stuff, like how to run meetings, have conversations, and set goals", she has said.

OER Services (2017), in its chapter on "Current Developments in Management Practices" has highlighted the following forces shaping the modern management -

- $\quad$ Pace of Change

- Technology

- Globalization

- Diversity

- Social expectations

It has stated two major developments in Management. One is that Management has become more specific with the formation of different disciplines and second is that Management has also become more general.

McKinsey (2016) in his book has observed that “A 2015 analysis of McKinsey's Organizational Health Index showed that companies with both speed and stability have a $70 \%$ chance of being ranked in the top quartile by organizational health. That's a far higher proportion than McKinsey found among companies focused only on one or the other. We have long established that organizational health is itself a predictor of strong financial performance."

Daniel Paulino Teixeira Lopes (2014), in their study on Brazilian firms found that innovation involves diverse phenomena and that there is a strong interrelation between technological innovation in products and processes and management and organizational innovations.

William B. Abernathy (2011) in his study "An analysis of the effects of selected management practices on organizational productivity and performance" found that "Twelve of the 20 management practices surveyed significantly correlated with organizational productivity, with performance management practices yielding the most significant relationship."

Nicholas Bloom et.al (2011) have concluded by saying that "Studying the causes and implications of variation in productivity across firms has become an important theme in social science. While several fields have been studying management for many decades, economists have traditionally ignored management as a driving factor explaining differences in productivity. We believe the discipline would benefit from more interaction with the management field. We have started to bridge this gap by developing a simple methodology to quantify some basic aspects of management practices across sectors and countries, and use experiments to identify causal impact.”

Sudatta Ranasinghe (1999) in his articles on Best Management Practices has given the following as the best management practices. 
Table 1

\begin{tabular}{|l|l|}
\hline \multicolumn{1}{|c|}{ Focus } & \multicolumn{1}{c|}{ Best Practice } \\
\hline I. External Customer & $\begin{array}{l}\text { Personalized long-term relationship with the } \\
\text { customer }\end{array}$ \\
\hline II. Internal Processes & Taking care and being fair \\
\hline a. People & Develop care-skills and recognize achievers \\
\hline b. Human resource development & $\begin{array}{l}\text { Outsource business operations and add value to } \\
\text { partner's work }\end{array}$ \\
\hline c. Products/Technology & $\begin{array}{l}\text { Integrate diagnostic and interactive controls } \\
\text { through a blend of technical and human systems. }\end{array}$ \\
\hline d. Process controls & \\
\hline
\end{tabular}

\section{OBSERVATIONS, GAP AND CONCLUSIONS}

Based on a collective consideration of the research material, the following could be deduced-

- Agencies have vouched for a promising outlook for both Indian Automobile and Auto Ancillary units in the years to come. They are quite upbeat about the growth in the near future for the Auto Ancillary units.

- They have highlighted the challenges like cost competitiveness, managing change, managing flexibility, innovation etc.

- At the same time there are articles that highlight the fact that even a company like Google focusses on doing the basics right.

- Most of the research is concentrated on dealing with technical issues of the Auto Ancillary units including things like green technology etc. Hence the research gap is quite apparent. Studies probing the impact of Organization and Management Practices on the performance of the Auto Ancillary units are very few. Further, most of the studies have focused on select themes like innovation or R \& D etc. A holistic study covering various facets of $\mathrm{O}$ $\& \mathrm{M}$ and its impact on the performance of the Auto Ancillary units has not been found.

\section{REFERENCES}

1. CARE Ratings (2017), Automobile Components: Structure and Prospects

2. Daniel Paulino Teixeira Lopes and Allan Claudius Queiroz Barbosa (2014), Management and organizational innovation in Brazil: evidence from technology innovation surveys, http://www.scielo.br/scielo.php?script=sci_arttext\&pid=S0103-65132014000400012

3. Economic Times, (2018), "ICRA upgrades Indian auto component industry's growth to 13-15\% in FY18"

4. e-Research \& Publications (2011), Snapshot - Auto Ancillary Industry in India

5. EY, (2011), Mega trends shaping the Indian passenger vehicle industry

6. ICICIdirect.com (2014), Auto ancillary sector update - The components industry to vroom ahead!

7. India Briefing (2018), “Auto Components Manufacturing in India: Robust Investment Outlook, Growth Potential”

8. India Research and Ratings (2017), Auto Ancillaries FY19 Outlook: Healthy OEM Demand and Technological Advancements to Drive Growth 
9. Kiel Institute Unit: Global Division of Labor, (2018)German management and organizational practices survey (gmop), https://www.ifw-kiel.de/institute/research-consulting-units/global-division-of-labor/projects/german-management-andorganizational-practices-survey-gmop/

10. KPMG, (2010), The Indian Automotive Industry - Evolving Dynamics

11. McKinsey (2005). Vision 2015 for the Indian Automotive Components Industry, Automotive Component Manufacturers Association of India and McKinsey and Company.

12. McKinsey (2016), McKinsey on Organization Agility and Organization Design

13. Sidin, J. P., \& Wafa, S. A. W. S. K. (2014). Quality management implementation and quality of production in Malaysia's manufacturing companies. International Journal of Research in Business Management, 2(3), 53-60.

14. McKinsey and Company, (2018), The future of mobility in India's passenger-vehicle market

15. Narayanan, K. (2006). Technology Acquisition and Export Competitiveness: Evidence from Indian Automobile Industry, in S.D. Tendulkar, A. Mitra, K. Narayanan and D.K. Das (eds), India: Industrialisation in a Reforming Economy, Academic Foundation, New Delhi, pp. 439-470.

16. Nicholas Bloom, Christos Genakos, RaffaellaSadun and John Van Reenen, (2011), Management Practices Across Firms and Countries, HBS WP, 12-052, December 19. 2011

17. Nicole Papa (2017), Organizational Management \& Leadership Practices That Impact Organizations, https://bizfluent.com/list-6724090-organizational-leadership-practices-impact-organizations.html

18. OER Services (2017), Current Developments in Management Practices, https://courses.lumenlearning.com/sunyprinciplesmanagement/chapter/reading-current-developments-in-management-practices/

19. Piplai, T. (2001). Automobile Industry: Shifting Strategic Focus, Economic and Political Weekly, 36(30), pp. $2892-2897$.

20. Toby, A. (2014). Working capital management policy and corporate profitability of Nigerian quoted companies: A sectoral analysis. International Journal of Financial Management, 3(1), 9-20.

21. RaffaellaSadun (2017) “Google’s Secret Formula for Management? Doing the Basics Well”, HBR, August, 2017

22. Sharma, S. (2006). A Study on Productivity Performance of Indian Automobile industry: Growth Accounting Analysis, Available at http://www.uq.edu.au/economics/appc2004/ Papers/cs6C4.pdf.

23. Shoko Haneda andKeiko Ito (2017), Organizational and human resource management and innovation: Which management practices are linked to product and/or process innovation?, Research Policy, Volume 47, Issue 1, February 2018, Pages 194208

24. SudattaRanasinghe, (1999), Five Best Management Practices in High Performing Companies in the Trading Sector of Sri Lanka, Journal of Comparative International Management, Volume 2 Number 1 June 1999

25. Nazneen, A., Bhalla, P., \& Zafar, S. (2014). A Comparative Study of Organizational ROLE Stress (ORS), Stress Tolerence Level and Its Management Among the Top Executives of Indian Public and Private Enterprises. International Journal of Business Management \& Research, 4(3), 85-94.

26. Veloso, F. and R. Kumar. (2002). The Automotive Supply Chain: Global Trends and Asian Perspectives, Economics and Research Department Working Paper Series No: 3, Asian Development Bank.

27. William B. Abernathy (2011), "An analysis of the effects of selected management practices on organizational productivity and performance" https://onlinelibrary.wiley.com/doi/pdf/10.1002/pfi.20225 